\title{
Analysis of Design Directions for Ground Control Station (GCS)
}

\author{
Yongjin (James) Kwon ${ }^{*}$, Jinyeong Heo ${ }^{1}$, Sekyung Jeong1, \\ Seunghee $\mathbf{Y u}^{1}$, Suhwan Kim${ }^{2}$ \\ ${ }^{1}$ Department of Industrial Engineering, Ajou University, Suwon, South Korea \\ ${ }^{2} 1^{\text {st }}$ Division, $3^{\text {rd }}$ Department, Agency for Defense Development, Daejeon, South Korea \\ Email: *yk73@ajou.ac.kr
}

How to cite this paper: Kwon, Y. (James), Heo, J., Jeong, S., Yu, S. and Kim, S. (2016) Analysis of Design Directions for Ground Control Station (GCS). Journal of Computer and Communications, 4, 1-7. http://dx.doi.org/10.4236/jcc.2016.415001

Received: July 12, 2016

Accepted: November 25, 2016

Published: November 28, 2016

\begin{abstract}
This study is a preparation phase for integrated visualization of battlefield situation. To develop the ground control station for unmanned systems, many factors have to be considered from the design stages, such as layout, information component, representation scheme, and human operation methods. Considering such many factors can be very difficult, hence we conducted an in-depth investigation of design factors from major UAV stations around the world. We analyzed the design characteristics and the specifics. In conclusion, we were able to derive some common aspects of design characteristics, which lead to the successful design approach.
\end{abstract}

\section{Keywords}

Ground Control Station, UAV, Human Machine Interface, Situation Awareness, Task Load

\section{Introduction}

Unmanned aerial vehicle (UAV) means the aircraft that remotely or autonomously controlled without a pilot. Ground control station (GCS) is designed to control the UAV from a remote distance. The mission and characteristics of the UAV is usually different from the manned aircraft, hence the design of the control station is differentiated. Due to distant control of UAV, the GCS displays must be designed to provide the enough level of situational awareness to the operators. Figure 1 shows the common characteristics of GCS. It is preferred that all mission flights can be conducted automatically with a minimal amount of human intervention. Human operators act as just a manger, and ensure that the mission unfolds as planned [1] [2]. 

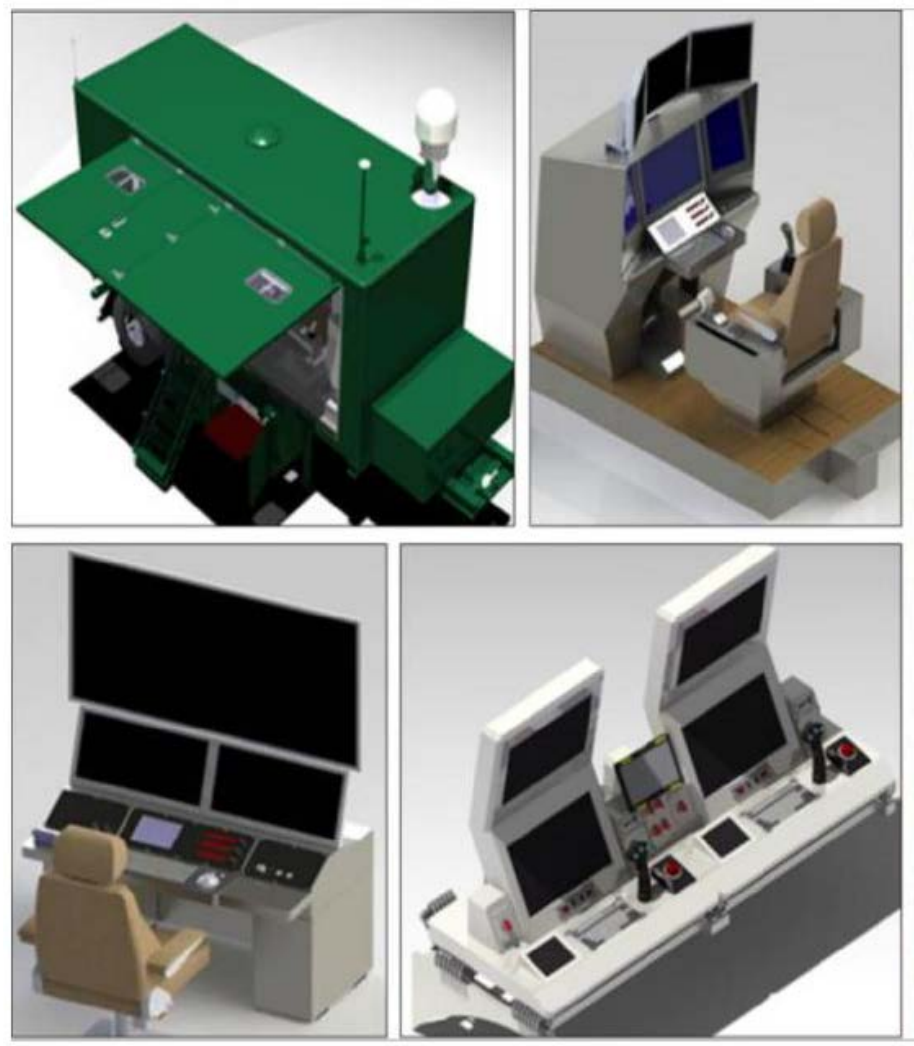

Mission planning

Map display

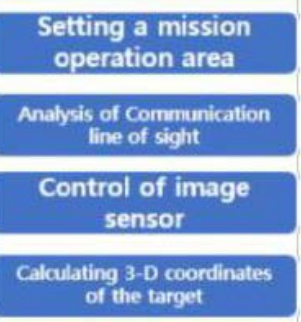

Wide area image generation

Video compression

and decompression

Flight Control

Attitude Control

State information display

Flight Inspection

Takeoff and Landing control

Figure 1. Representative features and various conceptual diagram for the ground control station

\section{Analysis of UAV GCS}

To develop the ground control station for unmanned systems, many factors have to be considered from the design stages, such as layout, information component, representation scheme, and human operation methods. Considering such many factors can be very difficult, hence we conducted an in-depth investigation of design factors from major UAV stations around the world. We analyzed the design characteristics and the specifics. Those include the screen display information, display method, number of screens, tactical situation information, operation of the tactical map equipment, number of operators, operator's position, layout, and the operation environment. By doing so, we derive the common aspects of design characteristics, which lead to the successful design approach. Here is the list of seven major UAVs: MQ-TB Hunter, Scout, Searcher-II, Hermes 450, MQ-1 Predator, Avenger, and Global Hawk. Figure 2 briefly illustrates the various GCS features, which bears much similarity among the different platforms [3] [4] [5] [6].

\subsection{UAV MQ-TB Hunter}

MQ-5 Hunter is an unmanned aerial aircraft, which was manufactured by the Israel aerospace industry. In the United States, Northrop Grumman also produced, and supplied to the US military. RQ-5 Hunter is a reconnaissance aircraft. MQ-5 Hunter is an 


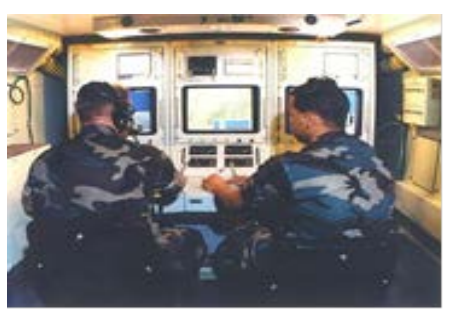

(a)

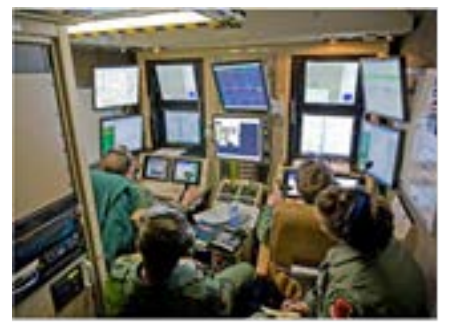

(d)

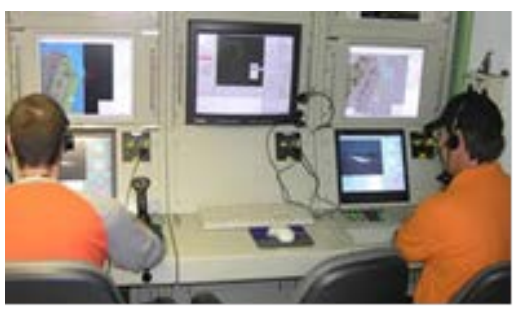

(b)

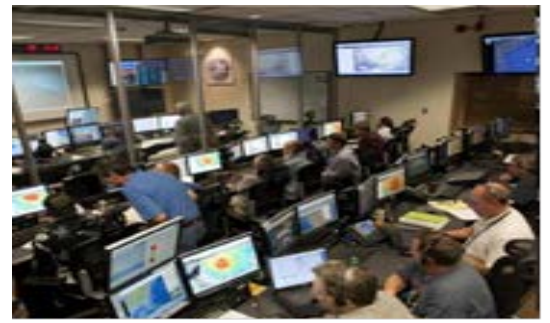

(e)

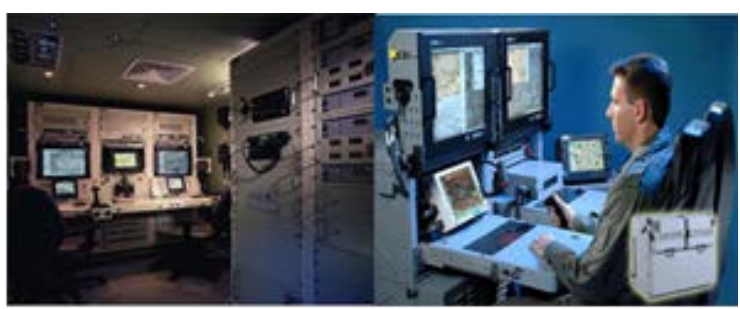

(c)

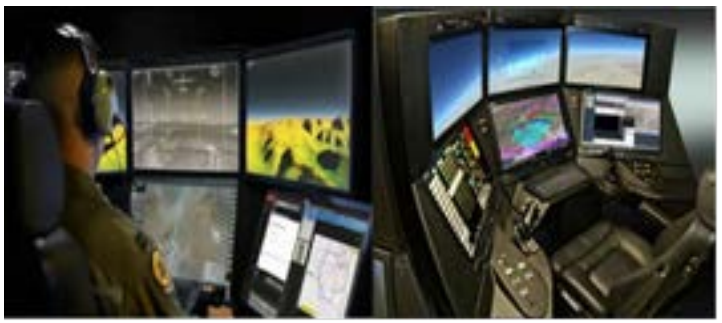

(f)

Figure 2. Various Ground control station design

attack version, which can carry the GBU-44/B laser-guided bomb that weighs about 20 $\mathrm{kg}$.

\subsection{UAV Scout}

Israeli Aviation Company developed the unmanned aircraft called Scout. It was being put into combat in 1982. To propel the Scout, a piston engine that mounts 13-foot propeller blade made of glass fiber is used. This UAV is very small in size, which emits a small radar cross section. It is nearly impossible to shoot down. Furthermore, it can transmit the real-time, 360-degree monitoring data via the central television camera. During the 1970s, the Israeli military was becoming increasingly interested in battlefield UAVs. The Scout had a similar configuration as the Mastiff, with a pusher propeller and a twin-boom tail. Table 1 illustrates the characteristics of both Hunter and Scout.

\subsection{UAV Searcher-II}

Searcher-II is produced by IAI-Malat, back in 1996. This aircraft has been deployed in the Indian Army and Air Force. More than 100 Searcher IIs are being operated by the Indian Air Force and the Indian Navy.

\subsection{UAV Hermes 450}

Israel, which has a state-of-the-art technology of the unmanned aircraft, has embarked aggressively on overseas sales of the above-mentioned drones. Recently, it is known for the focus on Indian market sales. Israeli Defense Ministry requests that the drone's flight performance should be important than the speed. It is also conjectured that the drones can substitute the conventional manned fighters. Currently, Israel leads the combat deployment of the Hermes 450 unmanned aircraft for long-term flight infor- 
Table 1. MQ-TB Hunter and Scout GCS design factors.

\begin{tabular}{ccc}
\hline Number of Screen & 3 & 4 \\
\hline Screen Layout & Line & Rectangle, Placed in the up and down \\
Touch interface & N/A & N/A \\
Number of Operator & Two or more & Two \\
Screen Style & Color coding & Color coding \\
Tactical Map Style & Color coding, 2D & Color coding, 2D \\
Interface & Button, Switch & Button, Switch, flight stick
\end{tabular}

mation collection. This is a large drone equipped with various sensors. Table 2 illustrates the characteristics of both Searcher and Hermes 450.

\subsection{UAV MQ-1 Predator}

Predator is a model that was developed by the General Atomics, Inc. It is considered as one of the most successful unmanned machines in the US Military. It is manufactured for reconnaissance, and called by the name RQ-1. It is also equipped with weapons. This variant is called MQ-1. Predator is a huge drone, and its large scale system requires the full-time personnel of about 55 people to operate. Predator can conduct an automatic flight along a path that has been programmed in advance. By using the satellite communication and the encrypted data link, it can fly anywhere in the world remotely.

\subsection{UAV Avenger}

Avenger is the combat drone that has been developed by the General Atomics Aeronautical System Company. It is one of the latest unmanned aircrafts of the US Army. In 2012, the company improved the ground control station. Avenger uses the same ground support infrastructure as the MQ-1 and MQ-9, including the ground control station and existing communications networks. Table 3 illustrates the characteristics of both Predator and Avenger.

\subsection{UAV Global Hawk}

Global Hawk is the product of the Northrop Grumman Corporation of United States. It is equipped with an all-weather synthetic aperture radar (SAR), electro-optical/infrared sensor (EO/IR), the moving target indicator, high-resolution electro-optical sensors, digital camera, and the third-generation infrared sensor. Its integrated sensor devices operate via a common signal processor that is comparable to the diameter of $1.2 \mathrm{~m}$ antenna and the supercomputer. Once it takes off, it can be flying up to 32 hours. It flies at a height that is not affected by the bad weather and the prevailing wind. Its flight altitude is out of anti-aircraft guns and most missiles intercept range. It is controlled via a dedicated radio channel and the satellite communication network. Table 4 illustrates the characteristics of Global Hawk. 
Table 2. Searcher-II and Hermes 450GCS design factors.

\begin{tabular}{ccc}
\hline Number of Screen & 5 & 4,5 \\
\hline Screen Layout & Rectangle, Placed in the up and down & Rectangle, Placed in the up and down \\
Touch interface & N/A & N/A \\
Number of Operator & Two or more & One or Two \\
Screen Style & Color coding & Color coding \\
Tactical Map Style & Color coding, 2D & Color coding, 2D, 3D \\
Interface & Buttons, Switch, flight stick, keyboard, mouse & Buttons, Switch, flight stick \\
\hline
\end{tabular}

Table 3. MQ-1 Predator and Avenger GCS design factors.

\begin{tabular}{ccc}
\hline Number of Screen & 12 or more & 6 \\
\hline Screen Layout & Rectangle, Placed in the up and down & Rectangle, Placed in up and down \\
Touch interface & Touch Screen & Touch Screen \\
Number of Operator & More than four & One \\
Screen Style & Color coding & Color coding \\
Tactical Map Style & Color coding, 2D, 3D & Color coding, 3D \\
Interface & Button, Switch, flight stick & Button, Switch, flight stick, keyboard \\
\hline
\end{tabular}

\section{Conclusion}

\subsection{Development Direction of the Ground Control Stations}

Most GCS design has been found that it provides enough level of battlefield information as well as the UAV flight information. It also emphasizes the minimization of the cognitive load. Operator reaction speed and accuracy are also very important. Improved visibility of battlefield situations has been realized using advanced graphical techniques, while enables the fast identification of threats. This early detection and identification of the magnitude of the threat allows the rapid decision making. The human interface is evolved into touch-screen and multi-screen system for fast reaction and vast presentation of necessary information. The individual convenience of the operator in terms of the configuration of a display screen has been implemented by the customization. A large screen is also being used to maximize the display size for information presentation.

\subsection{Analysis of Ground Control Station Design Factor}

Analysis of the unmanned system GCS, depending on the changing battlefield environment, has confirmed that the GCS is in the direction of maximizing quick judgment. The size of the screen tends to increase, as well as the number of screens. There is a tendency to place the screen up and down in order to reduce the fatigue of the operator. In addition, it uses a three-dimensional tactical map to express the battlefield situation in detail. The symbol for differing information has been classified by the colors. In order to reduce the work load of the pilots, additional operational personnel is present to work the system. Table 5 summarizes the findings. 
Table 4. Global Hawk GCS design factors.

\begin{tabular}{cc}
\hline Number of Screen & 12 or more \\
\hline Screen Layout & Various style \\
Touch interface & Touch Screen \\
Number of Operator & More than four \\
Screen Style & Color coding \\
Tactical Map Style & Color coding, 2D, 3D \\
Interface & Button, Switch, flight stick, keyboard, mouse \\
\hline
\end{tabular}

Table 5. Design directions for the GCS.

\begin{tabular}{|c|c|}
\hline Design direction & Details \\
\hline $\begin{array}{l}\text { Rapid situation } \\
\text { awareness }\end{array}$ & $\begin{array}{l}\text { Exhibition through a number of symbols and geographical data } \\
\text { Color coded for rapid recognition } \\
\text { Symbols are simple, yet effective }\end{array}$ \\
\hline $\begin{array}{l}\text { Battlefield } \\
\text { area settings }\end{array}$ & $\begin{array}{l}\text { Battlefield situation is represented with ease of understanding } \\
\text { User can zoom in or zoom out of display } \\
\text { Display can be providing an enlarged view of a particular area, } \\
\text { while simultaneously exhibits several display screens }\end{array}$ \\
\hline $\begin{array}{c}\text { Tactical } \\
\text { map style }\end{array}$ & $\begin{array}{l}2 \mathrm{D} \text { display or } 2.5 \mathrm{D} \text {, even } 3 \mathrm{D} \text { representation is possible, to indicate various enemies } \\
\text { threats, ballistic, and geo-features } \\
\text { User can set the style of representation to accommodate the varying situations }\end{array}$ \\
\hline $\begin{array}{l}\text { Information } \\
\text { concentration } \\
\text { on large screen }\end{array}$ & $\begin{array}{l}\text { A large color-screen is used to display the necessary information } \\
\text { The screen can be freely set in accordance with the operation }\end{array}$ \\
\hline
\end{tabular}

\section{Acknowledgements}

This work was supported by the Agency for Defense Development (ADD) under the Contract No. UD140066CD. The authors wish to express sincere gratitude for the financial support.

\section{References}

[1] Hong, J., Kim, S. and Kwon, Y. (James) (2015) Analysis of Modern Design Approach for Anti-Air Radar Screen. Technical Report of Ajou University, Suwon, South Korea.

[2] Jongsoon, I., et al. (2006) Study of Aircraft Landing Loads and Ground Handing Loads. Proceedings of The Korean Society for Aeronautical and Space Sciences, Fall Conference, 189-197.

[3] Jang, J., et al. (2011) Development of GCS for Small UAV with Automatic Takeoff and Landing Mode. Proceedings of The Korean Society for Aeronautical and Space Sciences, Fall Conference, 1637-1641.

[4] Backes, P.G., et al. (1995) Ground Control Station Development for the Dexterous Orbital Servicing System. Proceedings of the IEEE International Conference on Robotics and Automation, 21-27 May 1995, 1259-1264. http://dx.doi.org/10.1109/robot.1995.525454 
[5] Aydemir, M.E., et al. (2013) Ground Station Design Procedures for CANSAT. The 6th International Conference on Recent Advances in Space Technologies, 909-912.

[6] Olmos, O., et al. (2014) Tactical Displays for Combat Awareness: An Examination of Dimensionality and Frame of Reference Concepts and the Application of Cognitive Engineering. The International Journal of Aviation Psychology, 10, 247-271.

http://dx.doi.org/10.1207/S15327108IJAP1003 03

\section{Submit or recommend next manuscript to SCIRP and we will provide best service for you:}

Accepting pre-submission inquiries through Email, Facebook, LinkedIn, Twitter, etc.

A wide selection of journals (inclusive of 9 subjects, more than 200 journals)

Providing 24-hour high-quality service

User-friendly online submission system

Fair and swift peer-review system

Efficient typesetting and proofreading procedure

Display of the result of downloads and visits, as well as the number of cited articles

Maximum dissemination of your research work

Submit your manuscript at: http://papersubmission.scirp.org/

Or contact jcc@scirp.org 